Geopolítica(s) Revista de estudios sobre espacio y poder ISSN: 2172-3958

http://dx.doi.org/10.5209/GEOP.58132

\title{
Las series también tienen una geopolítica
}

Dominique Moïsi (2016) La géopolitique des séries ou le triomphe de la peur. París: Stock, 198 pp. ISBN 978-2-234-08047-8.

Dominique Moïsi acaba de publicar su última obra, titulada La géopolitique des séries ou le triomphe de la peur en la editorial Stock. Conviene recordar que el autor es actualmente asesor especial del IFRI (Instituto Francés de Relaciones Internacionales), tras haber sido su Director adjunto. Doctor en Relaciones Internacionales por la Universidad hebraica de Jerusalem, fue profesor en Universidades de reconocido prestigio internacional tales como La Escuela Nacional de Administración (ENA), la Escuela de Altos Estudios en Ciencias Sociales (EHESS) y el Instituto de Estudios Políticos (IEP) de París. Ha sido igualmente Visiting Professor en la Universidad de Harvard y en el King's College de Londres. Experto en geopolítica y especialista en política internacional, fue titular de la cátedra de Geopolítica europea en el Colegio Europeo de Natolin entre 2001 y 2008. Entre los libros publicados por Moïsi, podemos mencionar Le Nouveau Continent: plaidoyer pour une Europe renaissante, ${ }^{1}$ redactado junto con Jacques Rupnik, Les cartes de la France à l'heure de la mondialisation ${ }^{2}$ o La géopolitique de l'émotion: comment les cultures de peur, d'humiliation et d'espoir façonnent le monde ${ }^{3}$.

En el prólogo de su última obra, consagrada a la geopolítica de las series televisadas, el autor observa que, en la era de la globalización, la serie televisada se ha convertido en la referencia cultural universal cuyo análisis es fundamental para comprender las emociones a nivel mundial (pp.10-11). En efecto, las series se han convertido en

una dimensión esencial de la cultura. Sus guionistas [...] no se conforman con analizar fríamente la realidad. La sienten y la adivinan, gracias al poder de su intuición y [...] a la lucidez de su imaginación. De hecho, estos guionistas se han convertido en los mejores analistas de las sociedades y del mundo contemporáneo, e incluso en los más fiables futurólogos (p. 12).

1 D. Moïsi y J. Rupnik: Le Nouveau Continent: plaidoyer pour une Europe renaissante. París: Calman-Lévy, 1991.

2 D. Moïsi: La géopolitique de l'émotion: comment les cultures de peur, d'humiliation et d'espoir façonnent le monde. París: Flammarion, 2008.

3 D. Moïsi: Les cartes de la France à l’heure de la mondialisation, dialogue avec Hubert Védrine. París: Fayard, 2000. 
Moïsi constata que numerosas obras, algunas excelentes, han sido dedicadas al universo de las series televisivas. Pero, pocos geopolitólogos se han interesado por ese objeto, entre otras razones, porque esta temática se considera demasiado ligera, subjetiva y políticamente incorrecta en el mundo académico (p. 12). No en vano, ese desinterés carece de sentido en un contexto en el cual "las series han conocido una verdadera revolución cultural a lo largo de los últimos quince años. [...] Han alcanzado un nivel de excelencia desconocido hasta entonces" (pp. 12-13). Estudiar las series desde el punto de vista de la geopolítica se antoja ineludible porque "la geopolítica no se conforma con invadir literalmente lo real de nuestras vidas cotidianas, [sino que] invade nuestros imaginarios en un movimiento dialéctico irreversible" (p. 13).

Cada vez más, la realidad internacional se convierte en una fuente de inspiración para los guionistas de las series televisadas y, simultáneamente, las series se transforman en una fuente de inspiración para los actores del mundo, e incluso en la referencia principal para numerosos espectadores que perciben y analizan la actualidad internacional a través de ellas (p. 13). Para Moïsi, las series se han convertido incluso en fuentes de inspiración útiles para los propios responsables políticos y, a veces, en la mejor manera de difundir un mensaje a un público más amplio (p. 13). Más aún, "la serie se convierte en sí misma en el [centro] del debate político y emocional, como lo ilustra la polémica surgida en torno a Homeland en 2015" (p. 15). Dada la interconexión entre ambos mundos, conviene preguntarse ¿dónde empieza y dónde termina la ficción?, ¿dónde comienza y dónde acaba la realidad? (p. 15).

En la introducción de esta obra, Moïsi precisa los cuatro criterios que han prevalecido a la hora de elegir las series analizadas:

1) el éxito y, por lo tanto, la difusión de la serie;

2) el tema, en la medida en que la serie debe inscribirse en una reflexión que afecta directa o indirectamente a cuestiones geopolíticas;

3) la temporalidad, dado que la serie debe ser a la vez reciente y estar en proceso de difusión; $y$

4) la calidad (p.20).

Las cinco series seleccionadas, porque cumplen la mayoría e incluso la totalidad de estos criterios, son Game of Thrones, Dowton Abbey, Homeland, House of Cards y Occupied (pp. 20-21). Tres series son estadounidenses, una es británica y la última es noruega.

Para Moïsi, "las series se han convertido tanto en el revelador de los debates que agitan nuestras sociedades como en el espejo que nos remite a nuestros temores y esperanzas" (p. 22). Asimismo, las series pueden ser tanto una prefiguración de nuestro futuro como una reconstrucción, a menudo idealizada o al contrario dramatizada, de nuestro pasado, reflejando a veces nuestras preocupaciones actuales (p. 22). Según el autor de la serie Dowton Abbey, existe una nostalgia del orden y una necesidad inconsciente de gozar de reglas del juego estrictas. Es precisamente lo que ofrece esta serie a un público desorientado e incluso desamparado (p. 22). La serie televisada constituye igualmente un refugio exótico en el espacio y el 
tiempo. Más allá, algunas series, como Game of Thrones, son objeto de debates académicos en los departamentos de Relaciones Internacionales de ciertas Universidades, especialmente pertenecientes al mundo anglosajón. Desarrollan una "verdadera reflexión geopolítica, que refleja, de manera relativamente fiel, nuestra mezcla de fascinación y de temor hacia [un] sistema internacional caótico" (pp. 2425).

A ese propósito, conviene precisar que las series no son el monopolio de los Estados Unidos, aunque el espejo que ofrecen del mundo esté distorsionado por la dominación anglosajona en esta materia (p. 25). A su vez, "series televisadas tan prestigiosas como Homeland o House of Cards retoman unas series provenientes de otros lugares, a menudo con los mismos guionistas" (p. 25). Esta capacidad de los Estados Unidos para transformar una historia tomada en préstamo a otra cultura y de conferirle un sentido y una dimensión universal resulta de la familiaridad de una cultura que, a través del cine y posteriormente de la televisión, se ha impuesto a todo el planeta. Pero esta dominación cultural puede volverse contra los Estados Unidos porque el mensaje que difunden estas series es a menudo negativo, así como por la manera según la cual es recibido por los competidores y rivales de América (p. 27). Asimismo, "lo que transmiten las series que abordan más o menos directamente la geopolítica es, por lo esencial, una cultura del miedo y [...] un discurso que se halla en las antípodas de la Ilustración" (p. 28). En ese contexto, las imágenes de las series pueden preparar las mentes, mejor que cualquier libro o artículo, a la comprensión del mundo dado que permiten concretarlo y visualizarlo (p. 31).

En el primer capítulo del libro sobre la era de las series, Moïsi observa que "el 11 de septiembre de 2001 ha constituido un giro emocional, e incluso estratégico, en la historia reciente de los Estados Unidos y del mundo. A nivel de las emociones, hay un antes y un después el Nine Eleven. Nunca América se había sentido tan fuerte $[y]$ jamás se ha despertado tan vulnerable" (p. 33). Del día a la mañana, enfrentado al hiperterrorismo, la superpotencia ha descubierto su debilidad. La política internacional ha irrumpido con fuerza y brutalidad, y de manera espectacular, en la vida cotidiana de los ciudadanos norteamericanos (p. 34). No en vano, nos recuerda el autor, "la política internacional no había esperado el 11 de septiembre de 2001 para ser objeto de un tratamiento en el mundo de las series, [dado que] las cuestiones de geopolítica ya habían sido abordadas", a la imagen de The West Wing (p. 35).

Pero, después del 11-S, la temática internacional se ha convertido en ineludible. Las series integran esta nueva preocupación de manera directa en sus temáticas y de forma indirecta por el tono más grave y sombrío de numerosas series, de Breaking Bad a Walking Dead (p. 35). En ese sentido, el 11-S representa un giro fundamental pero contradictorio. Nunca los Estados Unidos han parecido tan vulnerables, pero, simultáneamente, jamás su soft power ha sido tan grande, como si existiese una relación inversamente proporcional entre la fuerza de un país y la seducción que ejerce su cultura (p. 36).

Haciendo un repaso histórico, Moïsi recuerda que, en los años 1980 y 1990, las series Dallas y Derrick, cada una a su manera, ejercieron una influencia geopolítica significativa (p. 37). Primera serie exitosa que acompañó la entrada en el universo de la globalización, Dallas fascinaba los telespectadores, no tanto por su intriga o 
la modernidad de sus personajes, como por el estilo de vida y la riqueza expuesta de manera ostentosa. De hecho, "el individualismo occidental, con la demostración de sus condiciones de vida lujosas [...] contenía un mensaje subliminal para los países del Tercer Mundo" (p. 38). En cuanto a la serie alemana Derrick, fue seguida con pasión durante los últimos años del régimen comunista, a ambos lados del Muro de Berlín. Los alemanes del Este estaban fascinados por el nivel de vida del Oeste. En ese sentido, nos dice el autor, "el inspector Derrick no ha derribado el Muro de Berlín, pero ha preparado su caída e incluso ha contribuido a ella, erosionando los fundamentos del discurso de la RDA" (p. 39).

Con el transcurso del tiempo, la referencialidad de estas dos series aparece anacrónica, ya que no se trata del mismo producto cultural que las series actuales. En efecto, las series de calidad aparecen realmente a finales de los años 1990 con The West Wing (p. 40). Varios factores son susceptibles de explicar esta evolución cualitativa:

- Con la cadena privada HBO, la serie adquiere sus letras de nobleza y gana una forma de libertad que era imposible en otras cadenas de televisión ( $\mathrm{p}$. 40).

- A nivel técnico, con la revolución del alumbrado, del encuadre y del montaje, las series entran en otro universo. Las fronteras que existían anteriormente entre ellas y el cine se difuminan progresivamente y las series dejan de ser los parientes pobres del género noble que es el cine (pp. 40-41).

- Realizadores de cine consagrados como David Lynch empiezan a contribuir con sus talentos a las series (p. 41).

La mejora de la calidad y la potenciación de las series se producen en el momento en el cual el 11-S transforma la relación de los Estados Unidos con el mundo y consigo mismo. Las series integran de manera indirecta el acontecimiento o reflejan su impacto en la sociedad (p. 41): "Puesto que el mundo exterior se interesa por él de la manera más negativa, queriendo destruirlo, América se interesa por el mundo de forma a menudo paranoica, a través de la teoría de la conspiración" ( $\mathrm{p}$. 42). Genera igualmente nuevos debates como el difícil equilibro a construir entre el respeto de la ley y la protección de la vida de los ciudadanos. Se trata de una cuestión central en Game of Thrones, The West Wing y Homeland (p. 42). De la misma forma, las series ofrecen un espacio a la autocrítica, sobrepasan algunos límites y rompen ciertos moldes. De hecho, "más allá de la intriga de estas series, lo que llama la atención del público globalizado [...] es la capacidad de la primera potencia mundial a hablar de sí misma sin el menor tabú” (p. 44). En ese sentido, las series contemporáneas realizan un ejercicio de desacralización del poder. La América conquistadora, optimista y moral de los años 1960 y 1970 ha dejado lugar a una América preocupada por su identidad y su futuro (p. 47).

Esto se produce en un periodo en el cual la geopolítica se ha puesto de moda. Durante décadas, subraya Moïsi, se hablaba de política extranjera y, posteriormente, de relaciones internacionales. "Pero, porque los diplomáticos no son los únicos protagonistas [y] porque los Estados no son los únicos actores, el término de geopolítica se ha impuesto [...] para describir el conjunto de observaciones y razonamientos estratégicos, geográficos e históricos que permiten mejorar la comprensión 
de los conflictos" (p. 50). Básicamente, existen dos corrientes en materia de relaciones internacionales:

- La primera denominada realista considera que los seres humanos están fundamentalmente motivados por los intereses personales y el ansia por el poder. Para Maquiavelo y Hobbes, el soberano que reina sobre un país es el único capacitado para garantizar la paz porque es el único en poder imponerla. Por lo cual, debe acumular el mayor poder posible para poder defender y promover el interés nacional y la riqueza es indispensable para garantizar el poderío militar (p. 51).

- La segunda pone el énfasis en la interdependencia e insiste en el rol desempeñado por los actores no-estatales como las empresas multinacionales o las organizaciones transnacionales. Según esta corriente, la política militar habría dejado de ser el elemento central y estaría prácticamente desfasada (p. 51).

En general, las series televisadas basan su relato en el esquema realista, a la imagen de Game of Thrones y House of Cards. Como lo subraya Moïsi, "en las series [de carácter] geopolítico, el actor clave sigue siendo el Estado-nación [...] Un Estado que controla un territorio cuyas fronteras están bien [delimitadas], una población permanente y un gobierno capaz de mantener unas relaciones internacionales con otros Estados. Esto presupone que ese Estado tenga el monopolio del control de las fuerzas armadas en el interior de sus fronteras" (p. 52). El problema es que, en ciertos casos, el Estado y la nación no coinciden. De hecho, el enfrentamiento existente entre Estados y naciones constituye una de las características principales de las relaciones internacionales contemporáneas. Asimismo, a pesar de que los individuos jueguen un papel relevante en la historia en general y en las relaciones internacionales en particular, numerosas series difunden la idea según la cual nos encontraríamos en un avión sin piloto: "Esta impresión de pérdida de control aparece a diferentes niveles en todas las series televisadas analizadas" (p. 54).

La sensación de caos que predomina, como consecuencia del desorden mundial, resulta de varios factores: 1) Occidente ha dejado de dominar el mundo y ha perdido el estatus de modelo único; 2) la implosión de Oriente Medio, que se repercute en las demás regiones e incluso en el mundo entero, dado que se caracteriza hoy en día por su fragmentación, radicalización y extensión; 3) la vuelta al primer plano de una Rusia humillada y revisionista; y 4) la falta de liderazgo a nivel mundial (pp. 56-57).

En semejante contexto, [marcado por] la ausencia [...] de orden y de árbitro [incuestionable], parece normal, e incluso inevitable, que el tema que sirva de hilo conductor a un nivel geopolítico a las series actuales sea el del miedo: miedo del caos y del retorno de la barbarie [en] Game of Thrones; miedo del declive vinculado a la crisis de la democracia [en] House of Cards; miedo del terrorismo y la interrogación sobre la naturaleza de la amenaza y la identidad del enemigo [en] Homeland; miedo del paso a otro orden mundial que se acompaña de la nostalgia hacia un orden condenado [en] Dowton Abbey; y miedo de la ocupación rusa [en] Occupied (p. 58). 
En el capítulo dedicado a Game of Thrones, Moïsi observa que esta serie resume y agrega todos los miedos y las presenta como capas arqueológicas (p. 58): "En Game of Thrones, el orden que se derrumba no parece ser sustituido por otro orden" (p. 62). Su universo está dominado por la política y no por la economía, aunque ésta juegue un rol importante ya que es necesario financiar las guerras (p. 63). El relato realiza une reflexión feroz sobre la crisis de legitimidad de la política y de los responsables políticos. "Los que desean el bien son ingenuos e impotentes [mientras que] los que son puramente cínicos pueden sobrevivir más tiempo, aunque acaben siendo rápidamente las víctimas de sus propios cálculos" (p. 63). A su vez, el poder absoluto se traduce por la arbitrariedad más sanguinaria, en un mundo dominado por la violencia y el caos (p. 63).

Como lo precisa el autor, "la serie Game of Thrones es, con diferencia, la que ha generado más comentarios geopolíticos y políticos" (p. 65). Así, la revista norteamericana Foreign Policy ha transpuesto el mundo fantástico de la serie al Oriente Medio contemporáneo y tanto el semanario Time como el periódico Le Monde se han interesado igualmente por esta serie (p. 70). La especificidad de Game of Thrones no consiste solamente en su propensión a transgredir todos los tabúes de manera recurrente, sino en el hecho de hacer desaparecer de manera sistemática todos los héroes que podrían tener una dimensión positiva (p. 70). A su vez, plantea cuestiones esenciales desde el punto de vista geopolítico y que gozan de una gran actualidad tales como: ¿Qué es el poder? ¿Cómo se constituye un Estado? ¿Cómo abordar la cuestión de las fronteras? ¿Qué hacer con los refugiados? (pp. 71-72).

Para Moïsi, Game of Thrones no festeja solamente el triunfo del realismo político y del cinismo, sino que subraya la derrota de la moral, ya que los vencedores son sistemáticamente pragmáticos, mientras que los idealistas pierden siempre, incluso sus propias vidas (pp. 75-76). En ese sentido, el éxito de Game of Thrones no resulta solamente de la calidad de su realización, del juego de sus actores y de los entresijos de su intriga, sino también de las ideas que la subyacen: no hay principios que valgan y todo está permitido (pp. 79-80). Se añade a ello una temporalidad específica, dado que "el tiempo [de la serie es] una sucesión de acontecimientos, más espectaculares y brutales unos que otros" (p. 82). En suma, mezclando con destreza referencias literarias, religiosas e históricas diversas y aludiendo constantemente a la actualidad, además de hacer un llamamiento a los instintos menos nobles del ser humano, Game of Thrones consigue crear un universo bárbaro y fascinante que atrae a un amplio público (p. 82).

En el capítulo consagrado a Occupied o el retorno de la amenaza rusa, el autor observa que el guion de la serie es de una gran sutileza. Reúne, entremezclados, todos los temores de nuestro tiempo, del calentamiento climático a la crisis del modelo democrático fomentado por unos dirigentes políticos mediocres. Del auge del temor frente a la Rusia de Putin, al descrédito que han padecido la Unión Europea y los Estados Unidos a lo largo de los últimos años (p. 156). La serie noruega invita el telespectador a ver la realidad trágica tal y como es. En ese sentido, el ataque de Breivik ha supuesto un antes y un después. Y, frente a las amenazas que rodean el país, los responsables políticos aparecen como tiernos, ingenuos e insuficientemente preparados. Es especialmente el caso del héroe principal de la serie, el 
primer ministro ecologista Jesper Berg. Sus constantes retrocesos, sus dudas, su incapacidad para decidir y para mantener sus posiciones en el tiempo son prueba de ello (pp. 158-159).

A su vez, Rusia es presentada desde un punto vista cínico y brutal al representar una amenaza para Noruega. En ese sentido, "el retorno de la amenaza rusa en la temática de las series puede ser percibida como la prueba ineludible del éxito de la estrategia llevada a cabo por Putin. Rusia continúa existiendo [y] es ineludible, incluso en el imaginario de los guionistas de las series televisadas" (p. 161). En cuanto a la Unión Europea (UE), es retratada de manera severa y negativa. Encarnada por el representante de la UE en Oslo, es descrita como una traidora, además de estar dominada por Alemania y de abandonar sus principios fundadores (p. 162). El retrato del protector norteamericano, representado por la OTAN, no es más halagüeño ya que se muestra incapaz de asegurar la protección de Noruega y de su primer ministro. En definitiva, "Noruega debe entender que está solo" (p. 163).

$\mathrm{Al}$ término de la lectura de La géopolitique des séries ou le triomphe de la peur, el lector agradece la audacia del autor por abordar un tema original, el de las series televisadas, desde la perspectiva de la geopolítica, lo que constituye una novedad en sí. Sobre la base de un sólido bagaje científico en relaciones internacionales y tras realizar un serio trabajo de campo, visionando las distintas temporadas de cada una de estas series, el autor nos ofrece un análisis riguroso y exhaustivo de estas series que han ganado en calidad a lo largo de los últimos quince años y que mantienen una relación estrecha con la actualidad internacional. Esta obra se inscribe en la continuidad del libro anterior del autor dedicado a la geopolítica de las emociones donde analizó de manera pormenorizada cómo las culturas del miedo, de la humillación y de la esperanza forjan el mundo en el que vivimos. Gracias a un pensamiento articulado, un razonamiento coherente y una escritura fluida y legible, ajena al uso de cualquier jerga, propicia la comprensión de sus principales tesis.

En definitiva, la lectura de esta obra de uno de los geopolitólogos más originales en la actualidad a nivel internacional se antoja indispensable para comprender la influencia recíproca entre las series televisadas y las relaciones internacionales.

Eguzki Urteaga

Universidad del País Vasco

Departamento de Sociología y Trabajo Social Facultad de Relaciones Laborales y Trabajo Social E-mail: eguzki.urteaga@ehu.eus 